\title{
LA REVOLUCIÓN DE INDEPENDENCIA
}

\author{
Rodrigo Moreno Gutiérrez \\ Universidad Nacional Autónoma de México
}

\begin{abstract}
S i consideramos que la segunda mitad del siglo xx trajo conS sigo la consolidación profesional de la historia en México y en buena parte de América Latina, una publicación periódica mexicana, dedicada a la historia, que abarca con regularidad sistemática todo ese periodo ( $\mathrm{y}$ hasta nuestros días) se convierte en una atalaya privilegiada para evaluar las modulaciones de la producción historiográfica en general. Si a ese interés añadimos el atractivo de establecer un sesgo temático, el ejercicio ofrece posibilidades especialmente sugerentes para observar tendencias, enfoques y diálogos que, con el pasar de las décadas, fueron sedimentando una peculiar manera de entender un determinado pasado. Y si ese sesgo temático es el proceso independentista, la empresa no podría resultar más sugerente y significativa por tratarse de uno de los objetos de estudio predilectos y más prolíficos de la historiografía mexicana y mexicanista. Por fundacional, por polémica, por emblemática, por socorrida y hasta por inducida, la historiografía del proceso independentista mexicano permite como pocas evaluar impulsos y cadencias de interpretaciones, intereses y contextos.
\end{abstract}


Es en ese sentido que el presente artículo busca aportar un modesto y acotado balance de la historiografía independentista publicada en Historia Mexicana desde su fundación con el propósito de analizar la manera en que ha cambiado la interpretación de la independencia mexicana atendiendo a las variaciones temáticas y estilísticas, las perspectivas teóricas y metodológicas, la construcción y el uso de las fuentes, y en última instancia los sentidos subyacentes en los textos dedicados al proceso de independencia mexicana en esta revista. Para cumplir dicho propósito, no sólo se consideraron aquellos trabajos que tratan estrictamente sobre "la guerra de independencia", sino todos aquellos que, directa o indirectamente, bien por temática y objetivos o bien por la cronología involucrada, se refirieron al proceso independentista mexicano en particular, pero también al hispanoamericano en general.

Con dicho tamiz, la revisión de los índices de los 279 números de la revista que fueron publicados entre 1951 y 2020 arrojó un total de 192 textos dedicados, como ya señalé, directa o indirectamente al proceso independentista. Ese total está compuesto por 97 artículos, 71 reseñas, 8 comentarios documentales, 9 críticas bibliográficas o réplicas, 5 presentaciones de números especiales y 2 obituarios. De este corpus, 134 textos fueron escritos por autores $(70 \%)$ y 57 por autoras $(30 \%)$. Las siguientes líneas son el fruto del examen de esa riquísima muestra historiográfica.

Cabe añadir que, dada la cantidad y densidad de textos en que se basa este balance, y en consideración de la amplitud y riqueza de las temáticas y perspectivas de este número conmemorativo de la revista, mi aportación no pretende exhaustividad alguna sino impresiones generales y elementos de reflexión, acaso sustentados en un panorama muy a vuelo de pájaro de la peculiar producción independentista de estas siete décadas de Historia Mexicana, en plena sintonía con los útiles balances historiográficos especializados y correspondientes a lo escrito, 
en general, sobre este proceso histórico. ${ }^{1}$ Por ello, el orden de los siguientes apartados mantiene un criterio cronológico pero, por su propia naturaleza y por la limitación del espacio, procuré excluir las más de las veces las referencias puntuales a cada texto.

LOS AÑOS DEL HÉROE (1951-1969)

Durante la primera década de Historia Mexicana, la de 1950, la producción relacionada con la historia de la independencia estuvo plenamente identificada con el impulso conmemorativo del bicentenario del nacimiento de Miguel Hidalgo. La mayoría de los trabajos se dedicaron a facetas particulares del Padre de la Patria: el revolucionario, el intelectual, el teólogo. Las miradas a otros objetos de estudio terminaban, también, en el cura insurgente: la Historia de Méjico fue analizada para recuperar la forma en que Alamán pintó a Hidalgo, y la folletería de los años revolucionarios fueron estudiados para escudriñar las mil y una maneras en que el régimen descalificó al exrector nicolaíta y líder rebelde. De igual modo, algunos de los libros reseñados tuvieron por temática representaciones o episodios de Hidalgo.

Este panorama invita a pensar que por entonces primó una relativa personificación del proceso histórico, no únicamente visible en el asedio de la figura heroica de Hidalgo sino también en los acercamientos a la independencia a partir de otros personajes como Allende, Morelos, Abad y Queipo, Iturbide o, ya en los artículos de la década de 1960, Talamantes. La preferencia por analizar detalles, momentos, etapas o proyectos de sujetos concretos podría revelar un aparente consenso en la interpretación

\footnotetext{
1 Rojas, "Historiografía de la Independencia (siglo xx)”, pp. 97-137; Ávila y Guedea (coords.), La independencia de México; Ávila, "Interpretaciones recientes", pp. 17-39; Ávila y Guedea, "De la independencia nacional a los procesos autonomistas", pp. 255-276; Serrano Ortega, "Deshaciendo el consenso", pp. 120-148; MORENO GuTiÉRREZ, "La historiografía del siglo XXI sobre la independencia de México", pp. 24-35.
} 
general del proceso histórico. No parece haber debate sobre la trascendencia de la independencia en tanto destrucción revolucionaria de un régimen de sujeción colonial que dio paso decidido al estado nacional mexicano, como tampoco se disputó el protagonismo irremplazable de la insurgencia armada. La guerra fue una revolución y la revolución fue por la independencia (la única posible). No era necesario explicitar los motivos de esa guerra revolucionaria porque eran claros: la independencia y la libertad de la patria. En esa medida, examinar la etapa formativa, las disquisiciones intelectuales o los planes militares de sus líderes era, de un modo mucho más directo, conocer mejor aquella revolución que, por muy catártica que hubiese sido, fue una misma. Por ello no parece haber surgido la necesidad de escudriñar en sus bases o en su composición, pues se encontraban contenidas en sus dirigentes. Del mismo modo, los rivales, ya de pluma, ya de espada, también podían ser considerados por igual como representantes de un régimen opresor monolítico.

Sobre esa base, los esfuerzos se dirigieron a rastrear "antecedentes", "influencias", "ideas" e "ideologías”. No hubo disenso en torno a la centralidad del año de 1810 como clave de la explosión rupturista, pero hubo miradas atentas a 1808, por una parte, $\mathrm{y}$ al último tercio del siglo xviII, por otra, como marcos útiles para entender el "fermento revolucionario". Abad y Queipo o Primo de Verdad eran, cada uno a su modo, "precursores". Como ya han subrayado los balances de la historiografía de la independencia mexicana, ${ }^{2}$ en las décadas de 1940 y 1950 se revaloró la tradición del pensamiento católico español en tanto raíz de la ilustración hispánica y, por esa vía, del independentismo americano. Dicha revaloración se nota en los textos de esos años de Historia Mexicana en las constantes referencias a la obra de Gabriel Méndez Plancarte, por ejemplo, o en los afanes por

\footnotetext{
2 Ávila y Guedea, "De la independencia nacional a los procesos autonomistas novohispanos”, p. 256; ÁviLA, “Interpretaciones recientes”, pp. 18-20.
} 
encontrar la raíz iusnaturalista y suareciana de la “ideología” independentista novohispana, al grado de ver ahí el germen de “doctrinas democráticas” que, según esta interpretación, necesariamente habrían de nutrir tanto las discusiones del verano mexicano de 1808 cuanto la política insurgente. No obstante, los afanes genealógicos por encontrar padres ideológicos de la independencia mantuvieron presente el vínculo con la Ilustración francesa y en particular con Rousseau.

Quizá el caso más significativo de la primera década es Luis Villoro. En el número 6 de la revista publicó "Hidalgo: violencia y libertad", justo un año antes de la aparición de su seminal libro La revolución de independencia y casi como avance de aquellos planteamientos. En aquel artículo de sorprendente potencia tan filosófica como poética, Villoro interpretó la temeridad libertaria de Hidalgo a partir de la lectura de las actas de su proceso civil. Desde ahí pintó con brío muralista a un Hidalgo decididamente independentista, soberbio juez y dueño de sus actos. En el cura de Dolores, Villoro vio la lúcida y aguda, impetuosa y frenética encarnación de la comunidad humana; por eso Hidalgo comulgó tan espontáneamente con el pueblo, y por eso el colectivo y no el monarca o la divinidad tenía que ser el fundamento del nuevo orden social. La libertad como vértigo contagioso y seductor se había transmitido eléctricamente del sabio rebelde a las masas insurreccionadas. En Villoro la revolución, valor en sí mismo, creó la fatal inmediatez de un presente que sólo podía terminar en su realización y en la muerte del elegido para restablecer un caos tan originario como apocalíptico: "Este panorama salvaje y grandioso [escribe Villoro], en que se desencadenan las fuerzas más profundas de la sociedad, desfila ante los ojos de Hidalgo poco antes de su muerte". ${ }^{3}$ Consumado el sacrificio del héroe sólo había dos posibilidades: la violencia y la libertad.

3 Villoro, "Hidalgo: violencia y libertad" (6), oct.-dic. 1952, pp. 223-239, en especial p. 234. 
Villoro rechazó el pesar o el arrepentimiento de Hidalgo por haber propiciado la revolución debido a que esta era la independencia y porque la independencia solo podía tener un fin: la libertad. Quedó, eso sí, el remordimiento cristiano por haber desatado la violencia y precisamente por eso Hidalgo encarnó, para Villoro, el drama de (nuestra) libertad caída. Y creo que Villoro es el caso más significativo de la primera década de la revista no sólo por este artículo sino por el impacto inmediato que generó su libro, visible por ejemplo en las tres reseñas que se le dedicaron en Historia Mexicana en los años siguientes.

Villoro también ejemplifica el variado perfil de los autores de los textos de esos años. En la primera década de la revista conviven tres generaciones: primero la de aquellos que, desprovistos de formación académica y provenientes de otros campos como la abogacía, ejercieron el oficio de la historia con la perseverancia que les exigió la rudeza de la primera mitad del siglo xx mexicano, sea por caso Alfonso Teja Zabre, quien, por cierto, como Villoro con las actas del proceso civil de Hidalgo, elaboró toda una interpretación del pragmatismo guerrero de Morelos a partir de la exégesis de un proyecto atribuido al cura michoacano. ${ }^{4}$ Después, la generación en plenitud de desarrollo e integrada tanto por juristas cuanto por filósofos que ejercieron ocasional o sistemáticamente la historia, como Felipe Tena Ramírez o Juan Hernández y Luna, o que terminaron convirtiéndose en historiadores de tiempo completo, como Ernesto de la Torre, Manuel Carrera Stampa, Xavier Tavera Alfaro y José Miranda. En esa misma generación es posible ubicar también a historiadoras plenamente reconocidas como tales y por tanto pioneras de la historiografía mexicana y mexicanista, como Nettie Lee Benson, Catalina Sierra o María del Carmen Velázquez. Por último, la revista también acogió a algunos jóvenes historiadores

4 Teja Zabre, "Morelos, hombre de guerra y hombre de paz" (32), abr.-jun. 1959, pp. 499-511. 
que se encontraban aún en proceso de formación o de especialización, como Luis González y González o Moisés González Navarro. Por perfil, a Villoro le correspondería más el segundo grupo, pero por edad este último pues no contaba ni 30 años cuando publicó el artículo de marras.

De igual modo, el texto de Villoro ilustra el estilo y las formas de los textos de aquellos años en que predominaba el tono ensayístico. Desprovistos de estados de la cuestión y a veces de objetivos, conclusiones, bibliografías o notas al pie, los artículos cabalgaban entre el apego a una reducida selección de documentos y los excesos líricos. Ninguno alcanzó el delicado equilibrio de Villoro, pero varios lo intentaron.

En términos temáticos es justo señalar que no todo fue Hidalgo en esos años. También hubo trabajos que rebasaron el ámbito novohispano y trataron, por ejemplo, la presencia de las independencias hispanoamericanas en la prensa estadounidense contemporánea, la “influencia” de los jesuitas en las conciencias criollas americanas y en las independencias, o los orígenes y el desarrollo del liberalismo español. Con diferencia, el principal abrevadero documental de la inmensa mayoría de los textos fue la Colección de Juan Hernández y Dávalos.

La década de 1960 no logró ensanchar más los horizontes y la presencia de textos referentes a la independencia se redujo a la mitad (11 contra los 22 de la década de fundación). Los artículos mostraron una relativa estandarización metodológica y se ocuparon de objetos más precisos, como el de Anna Macías sobre las imprentas insurgentes y la publicación de la Constitución de Apatzingán, o el original y riguroso acercamiento de Óscar Acevedo al carlotismo. ${ }^{5}$ Otro rasgo característico de los años sesenta fue la diversidad de formatos de las

${ }^{5}$ Macías, "Cómo fue publicada la Constitución de Apatzingán” (73), jul.-sep. 1969, pp. 11-22; AcEvedo, "El carlotismo en México” (42), oct.-dic. 1961, pp. 263-272. 
colaboraciones, pues los artículos y las reseñas ("examen de libros”) convivieron con balances historiográficos, bibliografías comentadas, notas sobre conjuntos documentales o sobre fragmentos de documentos. Esfuerzos como el de María del Carmen Velázquez por sintetizar y comentar todo lo publicado en los últimos 25 años sobre la independencia mexicana se harían simplemente inconcebibles después. ${ }^{6}$

Las reseñas fueron pocas pero certeras al llamar la atención sobre tres publicaciones mexicanistas que habrían de convertirse en referencias imprescindibles para sus respectivas temáticas: Mexico and the Spanish Cortes, editada por Nettie Lee Benson; Crown and Clergy in Colonial Mexico, de Nancy Farriss (ambas obras reseñadas por Andrés Lira), y The Hidalgo Revolt, de Hugh Hamill (reseñado por José María Muriá). En lo sucesivo, los asuntos relacionados con las Cortes de Cádiz, con el clero como factor social y político, o con la primera insurgencia, respectivamente, habrían de andar por las sendas anunciadas por estos autores. En esa medida no me parece menor la labor noticiosa de la revista que, al advertir la importancia de las novedades historiográficas, despertaba las inquietudes del gremio en años en los que la circulación de las publicaciones era extremadamente restringida. Me parece que ése fue el espíritu que animó también las notas sobre bibliografías, archivos, colecciones o catálogos que buscaron alertar a estudiantes y especialistas sobre la riqueza o las posibilidades de fondos que, con frecuencia, se encontraban fuera de México, como el catálogo de publicaciones de una librería española comentado por Carlos Olmedilla o una colección documental de la Biblioteca del Congreso atribuida al presbítero Joaquín Ávila, examinada por Vicenta Cortés. ${ }^{7}$

6 Velázquez, "Historia de la independencia de México" (60), abr.-jun. 1966, pp. 560-579.

7 Olmedilla, “México, 1808-1821” (36), abr.-jun. 1960, pp. 586-600; CoRTÉs Alonso, "Examen de Archivos. Miscelánea sobre la Independencia" (41), jul.-sep. 1961, pp. 157-160. 
ESTRUCTURAS, REBELIÓN Y POLÍTICA (1970-1989)

En la década de 1970 Historia Mexicana fue adquiriendo su tono definitivo. Se hizo patente la preocupación por dialogar historiográficamente, contrastar pareceres y, en fin, construir conocimiento como labor colectiva más gremial que propiamente científica. Aparecieron las notas al pie y los objetos de estudio fueron cada vez más acotados, sin que se llegara a abusar de la bibliografía ni de la documentación. La estabilización de los formatos fue depurando la heterogeneidad previa y se consolidaron los artículos y las reseñas como pilares de la revista. La década significó un modesto aumento de la producción independentista (8 artículos, 8 reseñas, 2 comentarios documentales) que volvió a desplomarse en los años ochenta (4 artículos, 2 reseñas del mismo libro y 2 comentarios documentales), década en que la revista reflejó esa suerte de relativo aletargamiento de los estudios sobre la independencia.

Vistos en conjunto, en estos 20 años los temas propiamente insurgentes perdieron vigor. Solamente Anna Macías siguió profundizando con meticulosidad la autoría de la constitución de Apatzingán; Ernesto de la Torre rastreó "ideólogos", "principios libertarios" e "influencias" de la institucionalidad judicial insurgente; y, más tangencialmente, Matt Meier abordó el conflicto a partir de los cultos devocionales ejemplificados por el enfrentamiento entre la Guadalupe insurgente y la Remedios gachupina. ${ }^{8}$ En cambio, las tendencias historiográficas en boga provocaron consideraciones más estructurales o estructuralistas. Los impactos de los estudios cuantitativos de corte socioeconómico ${ }^{9}$ son visibles en el artículo de María Dolores Morales sobre la demografía y el urbanismo de la ciudad de México al analizar

8 Macías, "Los autores de la constitución de Apatzingán” (80), abr.-jun. 1971, pp. 511-521; Torre Villar, "La génesis” (137), jul.-sep. 1985, pp. 131-172; Meier, "María insurgente” (91), ene.-mar. 1974, pp. 466-482.

9 Rojas, "Historiografía de la independencia (siglo xx)", pp. 128-129. 
el padrón de propietarios de 1813, del mismo modo en que la recuperación del reformismo borbónico como "antecedente" de las revoluciones independentistas aparece con claridad en la mirada de Richard Garner sobre la Real Caja de Zacatecas. No obstante, creo que el artículo que ejemplifica mejor los planteamientos de estos años es el de Enrique Florescano sobre el problema agrario novohispano en las primeras dos décadas del siglo XIX. ${ }^{10}$ Florescano buscó (y encontró) en el campo las injusticias y las incongruencias del sistema colonial, expresadas en el latifundismo y la acumulación, el empobrecimiento y el acaparamiento. Rastreó los asomos de los reclamos agrarios en la insurgencia, pero sin la menor intención de encontrar ahí algún "Zapata en sotana" sino para advertir que la de independencia fue una revolución política, no social, cuya dirigencia criolla subordinó los padecimientos de la "masa" de indios y castas que por 300 años padeció, según su interpretación, la misma servidumbre.

El marco independentista hispanoamericano se mantuvo presente gracias a las consideraciones de Francisco Cuevas Cancino sobre la Carta de Jamaica, a la reseña que el mismo Florescano publicó sobre The Spanish American Revolutions de John Lynch, y a las aventuradas aproximaciones de Guadalupe Jiménez Codinach al ámbito de las conspiraciones, los exilios y las sociedades secretas. ${ }^{11}$ Otras dos temáticas se mantuvieron latentes en estos años: por una parte Cádiz, con las notas de Dorothy Tanck sobre la educación discutida por el constituyente gaditano y sus particularidades proyectadas en el ámbito novohispano, y con la interesantísima recreación que Nettie

10 Morales, “Estructura urbana” (99), ene.-mar. 1976, pp. 363-402; GARner, “Reformas borbónicas” (108), abr.-jun. 1978, pp. 542-587; Florescano, “El problema agrario” (80), abr.-jun. 1971, pp. 477-510.

11 Cuevas Cancino, “Una nueva versión” (89), jul.-sep. 1973, pp. 145-175; Jiménez Codinach, “Confédération Napoléonnie” (149), jul.-sep. 1988, pp. 43-68. 
Lee Benson lograra del contexto político en que tuvo lugar la elección de Ramos Arizpe como diputado a Cortes; y, por otro lado, el estallido de la crisis política de 1808, con los eruditos comentarios de Hugh Hamill al discurso de Primo de Verdad, las notas de Manuel Calvillo sobre un proyecto constitucional de 1809, y la revisión de la coyuntura crítica que ofreció Hira de Gortari, atento a "sentimientos de autonomía" y a las reacciones de las corporaciones de la ciudad de México. ${ }^{12}$

Por cierto, esa búsqueda historiográfica por la autonomía, tan persistente en los siguientes años, De Gortari la encontró en el libro de Doris Ladd, The Mexican nobility at independence, que reseñara Tanck en Historia Mexicana en 1977. ${ }^{13}$ Además de las reseñas en los setenta a los libros de Romeo Flores Caballero (La contrarrevolución en la independencia), Javier Ocampo (Las ideas de un dia) y Timothy Anna (The Fall of the Royal Government in Mexico City), llama la atención que, ya en los años ochenta, el único libro de tópico relacionado con la independencia reseñado (por doble partida) en la revista fuera From Insurrection to Revolution in Mexico, de John Tutino, no por su innegable importancia sino por quedar así como único representante de aquellos estudios que se dedicaron a analizar patrones de comportamiento en las rebeliones campesinas y, desde ahí, renovaron el interés en los orígenes, raíces y composición de la insurgencia. ${ }^{14} \mathrm{El}$ modelo propuesto por Tutino fue cuidadosamente examinado y criticado por Claudio Lomnitz y por Mercedes de Vega en sus respectivas reseñas. Uno de los autores

12 Tanck de Estrada, “Las cortes de Cádiz” (113), jul.-sep. 1979, pp. 3-34; Benson, "La elección” (132), abr.-jun. 1984, pp. 515-539; Hamill, "Un discurso" (111), ene.-mar. 1979, pp. 439-474; GORTARI, "Julio-agosto de 1808" (153), jul.-sep. 1989, pp. 181-203.

13 Alfredo Ávila ha analizado en profundidad el origen y el desarrollo del planteamiento "autonomista" en la historiografía independentista: Ávila, “¿Autonomía o independencia?”, pp. 99-118.

${ }^{14}$ Un útil balance de dicha corriente puede verse en Hernández Jaimes, "Los grupos populares y la insurgencia”, pp. 65-84. 
relacionados con esa y otras renovaciones historiográficas fue Brian Hamnett, quien años antes había seguido la trayectoria realista de Anastasio Bustamante en un completísimo artículo que abrió sugerentes vetas sobre las posibilidades de análisis de la contrainsurgencia y la naturaleza de esa guerra que fue la de independencia. ${ }^{15}$

AUTONOMÍAS, CULTURAS, BICENTENARIOS (1990-2020)

La renovación historiográfica sobre las independencias cocinada en los años noventa ha sido bien estudiada. ${ }^{16} \mathrm{~A}$ falta de términos más precisos, cimentado en una "nueva historia política” el llamado "revisionismo" priorizó el estudio de la faceta política de estas revoluciones que, desde entonces, fueron interpretadas básicamente como un proceso (más lento y menos rupturista) de construcción de gobiernos representativos. Algunos de los principales protagonistas de esta y otras renovaciones dejaron su huella en los números de Historia Mexicana de esta década medular de la historiografía independentista: Tulio Halperin Donghi y Jaime E. Rodríguez O., como autores de artículos, y François-Xavier Guerra y Antonio Annino como coordinadores de obras colectivas reseñadas.

Es cierto que la presencia independentista no fue tan abrumadora en la revista de la década de 1990 como podría suponerse (13 artículos y 4 reseñas), pero las inclinaciones de los textos resultan muy ilustrativas. Por una parte, mayor interés por ampliar los horizontes mexicanos al mundo hispanoamericano mediante esfuerzos comparativos de fenómenos concretos (los consulados de México y Caracas y sus redes atlánticas; los catecismos patriotas y republicanos de los ámbitos rioplatense,

15 Hamnett, “Anastasio Bustamante” (112), abr.-jun. 1979, pp. 515-545.

16 Ávila, "Las revoluciones hispanoamericanas”, pp. 17-33; RoJas, "Historiografía de la independencia (siglo xx)”, pp. 132-137; GuEdEA, "La historia política”, pp. 52-64. 
chileno, neogranadino y novohispano; la utilización de lo indígena en las luchas políticas "criollas" independentistas), acercamientos a problemas necesariamente hispánicos (la política metropolitana hacia América en el Trienio Liberal y las posturas y gestiones de los diputados americanos en las cortes de Madrid) o síntesis interpretativas deliberadamente americanistas, como el apretado ensayo de Halperin Donghi sobre los usos o visiones del pasado a lo largo de dos siglos de reflexión hispanoamericana, o la recapitulación que ofrece Rodríguez $\mathrm{O}$. sobre todo el proceso independentista. ${ }^{17}$ Esta última, germen de La independencia de la América española que Rodríguez O. publicaría al poco tiempo, ya contenía el núcleo de su propuesta: las independencias (consecuencias, en sí mismas, de procesos de reestructuración imperial) fueron tanto sanguinarias y estériles guerras civiles "fratricidas", cuanto la persistente búsqueda de la "autonomía” y la construcción de un gobierno representativo, particularmente irradiado desde Cádiz; el primer aspecto ni podía ni pretendía ninguna revolución social y en todo caso legó una tendencia dictatorial, mientras que el segundo, en cambio, cimentó la participación, la democracia, el constitucionalismo y el parlamentarismo. En esta visión, Rodríguez O. ya perfilaba la primacía del "autonomismo" y de los "autonomistas" para explicar grupos y demandas políticas americanas desde los intentos juntistas de 1808 hasta el establecimiento de los estados nacionales en la década de 1820. Con el tiempo, Rodríguez O. iría radicalizando esta tesis hasta llegar a una sustitución terminológica (y tautológica) casi total de independencia por "autonomía".

El otro artículo de Rodríguez O. en estos años señala una más de las inclinaciones temáticas de las colaboraciones

17 Halperin Donghi, “Hispanoamérica en el espejo” (167), ene.-mar. 1993, pp. 745-787; RodríGuez O., "La independencia” (167), ene.-mar. 1993, pp. 571-620. 
independentistas de la revista en el decenio de los noventa: la revisión de la etapa conocida como "consumación de la independencia”. En concordancia con su propuesta general, Rodríguez $\mathrm{O}$. interpretó la independencia mexicana de 1821 como la concreción de los anhelos de autonomismo que se habían expresado coherente y persistentemente desde 1808 en conspiraciones y procesos electorales a lo largo de toda la década. En esta interpretación, el restablecimiento constitucional de 1820 habría permitido a los “autonomistas" el control de las instancias de gobierno provincial y local que, mediante una "extensa red autonomista”, generaron el nuevo gobierno mexicano evitando una revolución social. ${ }^{18}$ Otros artículos señalaron el interés de volver al estudio de esta etapa desde diferentes ángulos, como el papel social de las sucesivas fiestas de la transición (por la capitulación, por la jura del Plan de Iguala, por el establecimiento del Congreso y por la entronización de Iturbide) en una capital de provincia, como estudió Mariano Torres para el caso poblano; o bien la discusión de Jaime del Arenal sobre el significado de la constitución en el programa iturbidista desde la independencia trigarante hasta el Imperio. ${ }^{19}$

Además del hispanoamericanismo y el análisis de la "consumación", Historia Mexicana mantuvo en dos colaboraciones de los años noventa el interés por recuperar la dimensión bélica de la independencia. Particularmente sintomática fue, en este sentido, la dura crítica que hizo Christon Archer de un libro de Ernesto de la Torre en que, entre otras cosas, el especialista canadiense rechazó frontalmente el regreso a una historiografía nacionalista e insistió en entender la independencia como guerra civil que, por eso mismo, se vuelve elusiva a los criterios

18 Rodríguez O., "La transición de colonia a nación” (170), oct.-dic. 1993, pp. 265-322.

19 Torres Bautista, "De la fiesta monárquica” (178), oct.-dic. 1995, pp. 221-239; Arenal Fenochio, "El significado" (189), jul.-sep. 1998, pp. 37-70. 
encomiásticos de la heroicidad. ${ }^{20}$ En plena sintonía con este llamado, la revista publicó al poco tiempo un artículo en que Juan Ortiz analizó la situación (política, fiscal, defensiva) de las ciudades novohispanas de cara a la guerra independentista y a una insurgencia persistentemente rural. En esta mirada quedó manifiesto el empeño por examinar la gama de posibilidades que abrió la guerra y el tipo de decisiones, necesariamente contingentes, que tomaron o acordaron los grupos urbanos, así como las consecuencias descentralizadoras de esta dinámica de conflicto que terminó por debilitar en extremo al poder virreinal. ${ }^{21}$ También hubo interés en estos años por tratar el tema de los préstamos y los donativos recaudados en Nueva España en el periodo de la crisis política y la guerra peninsular.

La historiografía independentista en lo que va del siglo XxI ha marchado al ritmo de las conmemoraciones bicentenarias. La proliferación de publicaciones relativas a estas revoluciones demanda balances específicos, ${ }^{22}$ pero es importante subrayar que los bicentenarios también impactaron sensiblemente en la revista pues en estos últimos 20 años Historia Mexicana más que duplicó la cantidad de textos dedicados a la independencia con relación a los 50 años previos: en la década de 2000 aparecieron 48, y 68 en la de 2010. En gran medida este abultado aumento se debe a los números especiales destinados total o parcialmente a temáticas relacionadas con las independencias (en 2003 un número dedicado a la construcción de las naciones hispanoamericanas, en 2008 a la coyuntura de 1808, en 2009 a la independencia mexicana, en 2011 a algunos conceptos de la época de la transición y en 2019 al abolicionismo).

20 Archer, “Sobre Ernesto de la Torre Villar” (177), jul.-sep. 1995, pp. 161-165.

21 Ortiz Escamilla, “Las élites de las capitales” (182), oct.-dic. 1996, pp. 325-357.

22 Propongo uno en Moreno Gutiérrez, "La historiografía del siglo XXI sobre la independencia”. 
Y precisamente los números especiales ofrecen un valioso termómetro que mide, digamos, la temperatura historiográfica de las referencias cruzadas, las autoridades construidas, los intercambios y las temáticas de la que, en realidad, es ya nuestra actualidad. Por ejemplo, el número 210, coordinado por Tomás Pérez Vejo, ofrece, en conjunto, un panorama polifacético, coral, complejo y de largo plazo del problema de la nación mediante análisis de manifestaciones varias como el arte, la historiografía, la memoria, la imaginación o las identidades colectivas. En estos y otros textos es evidente el consenso en la interpretación de las independencias como el punto de partida (y nunca de llegada) de la construcción nacional, estatal e incluso identitaria. Por su parte, el número 229, coordinado por José Antonio Piqueras y dedicado a la "coyuntura germinal" de 1808, evidencia la plena incorporación del marco hispánico en la consideración del proceso independentista (aunque no necesariamente por medio de esfuerzos comparativos sino en tanto conciencia de la vasta diversidad integrada en una cultura política compartida). Bajo esa perspectiva se evaluaron problemas como la opinión pública, la soberanía, el constitucionalismo, el liberalismo, y cada uno de ellos en función de ámbitos, ciudades, cuerpos políticos y tendencias particulares. A partir de miradas colectivas como ésta se favoreció una interpretación acaso más coyuntural y política de la crisis de la monarquía y de las independencias, en plural. De manera significativa, por medio de posturas como las de José María Portillo Valdés o Antonio Annino se fue arribando a la consideración de Cádiz -ese fallido laboratorio del "cuerpo de nación"- como un doble fracaso constitucional (por imperial y por nacional) antes que como la otrora puerta a la modernidad política igualitaria y bihemisférica. ${ }^{23}$

${ }^{23}$ Portillo Valdés, “Crisis e independencias" (229), jul.-sep. 2008, pp. 99134; AnNino, "Imperio, constitución y diversidad” (229), jul.-sep. 2008, pp. 179-227. 
El dossier del año 2009, coordinado por Andrés Lira y dedicado especialmente a la independencia mexicana, ofrece otro espléndido mural de los tonos, preocupaciones, debates, alcances y límites de la agenda académica del bicentenario. Ahí se encuentran replanteamientos generales, profundizaciones específicas, revisiones necesarias y enfoques comparativos. No sólo figuran nuevos acercamientos a fenómenos relacionados con la cultura política y con las disputas por la legitimidad, sino que también se incorporan análisis relacionados con la guerra, la violencia y los usos y expresiones del odio. Artículos como el de Gabriel Torres Puga ilustran otra característica importante de estos años: la profundización sistemática de un aspecto puntual, pero con la sensibilidad de aportar a los debates historiográficos más robustos del momento. En este caso, por medio del análisis de las anomalías y alteraciones de los procedimientos que terminaron por derruir la autoridad de la Inquisición, Torres Puga en realidad explica la manera en que la revolución transformó la arquitectura institucional del antiguo régimen. Las contradicciones en que cayó el tribunal explican así el debilitamiento de los cimientos de la estructura política en su conjunto precisamente por el cambio de referentes de legitimidad..$^{24}$ Este número también ilustra, por un lado, la aparición de sujetos y ángulos casi ignorados por la historiografía tradicional y de los que la actualidad demanda su plena incorporación al análisis del proceso, verbigracia las mujeres que en estudios como los de John Tutino o María Antonieta Ilhui Pacheco figuran bien como transgresoras o rebeldes, bien como propietarias o rancheras y, en cualquier caso, como agentes de los cambios revolucionarios; $;{ }^{25} \mathrm{y}$, por otro lado, la recuperación de la insurgencia como objeto de estudio

24 Torres PugA, “Inquisidores” (233), jul.-sep. 2009, pp. 281-325.

25 Pacheco Chávez, “Rebeldes y transgresores” (233), jul.-sep. 2009, pp. 327 354; Tutino, “Soberanía quebrada” (233), jul.-sep. 2009, pp. 11-75. 
mediante acercamientos a etapas, personajes o regiones particulares o poco explorados.

A propósito, la propuesta de Tutino expresa otro giro analítico importante: el del culturalismo sobre el estructuralismo, sólo que en su caso se privilegia el problema del patriarcado para explicar por qué unos pueblos se rebelaron y otros no. El común denominador con los análisis de esta corriente es la búsqueda de patrones de comportamiento rural y la conclusión de que una era la insurgencia política y otras las insurgencias populares: el tipo de “autonomía” que buscaban era, a fin de cuentas, radicalmente distinta. Como es bien sabido, una de las obras más influyentes en este sentido fue La otra rebelión, de Eric Van Young, publicada y traducida algunos años antes y cuyo impacto desde entonces fue mayúsculo. Su presencia en Historia Mexicana quedó plasmada en el justamente célebre debate que el autor sostuvo con Alan Knight en 2004, auténtica joya de esgrima intelectual, crítica historiográfica e interpretación histórica y, lamentablemente, rara avis de nuestro medio y del cual la revista debe presumir y tratar de replicar. ${ }^{26}$ En ese intercambio se hizo patente el tránsito del enfoque político y de la clase cultural protagonizado por François-Xavier Guerra al enfoque culturalista y de cultura política popular simbolizado por Van Young. El debate refleja otra particularidad de los textos de estos años: el ejercicio de una crítica más frontal y la expresión abierta de reservas y reclamos a ciertas posturas. Además de la controversia Knight-Van Young contamos también con la respuesta de Roberto Breña a la reseña que de su libro escribió Josefina Zoraida Vázquez, o la aguda revisión que elaboró Elías Palti precisamente del dossier sobre la coyuntura de $1808 .{ }^{27} \mathrm{En}$ estos y muchos otros textos se nota no sólo una historiografía

26 Knight, “Crítica. Eric Van Young” (214), oct.-dic. 2004, pp. 445-515; VAN Young, “Réplica” (214), oct.-dic. 2004, pp. 517-573.

27 Breña, "Comentario” (230), oct.-dic. 2008, pp. 933-941; Palti, "Perspectivas plurales” (232), abr.-jun. 2009, pp. 1447-1476. 
madura y dialogante sino el papel de Historia Mexicana como necesaria tribuna gremial.

Lo cierto es que en torno a los bicentenarios apareció una mayor diversidad de actores colectivos y se estudiaron con mayor rigor expresiones de la violencia y sus muchas incidencias en la revolución, ambos aspectos a los que se arribó con metodologías más sofisticadas provenientes no pocas veces de las ciencias sociales y de la historia cultural. Exactamente en ese sentido es explicable el reclamo a la historiografía política que había prevalecido en la década anterior -que podría simbolizar el eje Guerra-Annino-Rodríguez (por llamarlo de algún modo)- y que demandó, ya en este siglo, la reconsideración de la insurgencia como un movimiento efectivamente anticolonial que involucró de modos diversos vínculos complejos entre élites urbanas y comunidades campesinas que terminaron por incidir de manera determinante en la revolución y en las transiciones políticas, interpretación que alcanza a vislumbrarse en la reseña que escribió Hamnett de la obra de Peter Guardino sobre la cultura política popular en Oaxaca. ${ }^{28}$

Los últimos años han asimilado algunas tendencias historiográficas que parecen complementarse. Por un lado, la consideración de los tiempos largos. Artículos, libros reseñados, críticas y números especiales en la década de 2010 muestran la adopción del siglo oculto en la "era de las revoluciones”, 17501850, como marco necesario para explicar las implicaciones del proceso que hizo ciudadanos donde había súbditos. Perspectivas como la historia conceptual revelaron la imposibilidad de explicar la magnitud y profundidad de los cambios sin el estudio de la dimensión lingüística de las revoluciones. El dossier del número 239, coordinado por Guillermo Zermeño, muestra la adopción de estas herramientas metodológicas que en el mundo hispánico fueron provechosamente impulsadas por Javier

${ }_{28}$ Hamnetт, “Sobre Peter Guardino” (225), jul.-sep. 2007, pp. 291-298. 
Fernández Sebastián. En ese ejemplar los autores convocados dieron seguimiento a conceptos como literatura, indio/indígena, policía, razón, cultura, casta/raza, historia y representación para explicar el desplome de la monarquía española a partir de las innovaciones y persistencias en el uso de términos y representaciones. Experimentos como éste y propuestas como las de varios de los libros reseñados dejaron ver la propensión a relativizar la importancia de la década revolucionaria en favor de la observación de continuidades o, lo que es lo mismo, la consideración de transiciones quizá más hondas pero sobre todo más lentas, enfoque que a la vez matizaba el carácter rupturista de las independencias y propiciaba la interpretación del nuevo orden como un proceso sinuoso y cansino íntimamente relacionado con la politización del lenguaje, de los "imaginarios" y de las identidades.

Pero, por otro lado, artículos y reseñas recientes exhiben el repunte del enfoque local o regional para explicar por medio de actores y espacios concretos la materialización cotidiana de la revolución y, aquí sí, de las rupturas. Esta perspectiva invita a pensar que entre los, digamos, macro (mundo atlántico o hispánico, imperios, hemisferios, continentes) y los micro encuadres (pueblos, provincias, regiones) cayó en desuso la perspectiva que había sido tradicionalmente privilegiada para los relatos independentistas: la nacional. De esta forma, resulta cada vez más convincente que el marco del estado nacional es hasta cierto punto estéril para comprender un proceso atravesado por el problema histórico de la nación.

En definitiva, los muchísimos textos relacionados con las independencias que ha publicado Historia Mexicana en los últimos años evidencian, en la sofisticación de los planteamientos y la densidad del diálogo historiográfico, la indudable vigencia de los análisis sobre este proceso revolucionario para explicar fenómenos históricos relacionados con la cimentación de lo público y lo político a través de prácticas colectivas, instrumentos 
normativos, diseños institucionales, aparatos fiscales, trayectorias intelectuales, actores armados y usos de la violencia.

\section{COMENTARIO FINAL}

No creo exagerado afirmar que el conjunto de textos relacionados con la independencia publicados en los dignísimos 70 años de Historia Mexicana brinda un inmejorable panorama de las cadencias y preocupaciones historiográficas generales sobre este proceso histórico. Del Hidalgo de Villoro al autonomismo de Rodríguez, del Morelos de Teja Zabre a la insurgencia popular de Van Young, es posible vislumbrar obsesiones, expresiones, marcos, argumentos, estilos, evidencias, deducciones, omisiones, fuentes, disputas y contextos. En una palabra: historiografía. Siete décadas ininterrumpidas de entusiasta producción académica que transita de los grandes hombres y las ideas universales a los lenguajes y la cultura política popular, de lo nacional a lo hispánico, de las estructuras a las coyunturas y de las colecciones documentales a los recursos electrónicos.

Valgan estas líneas no sólo para celebrar la incuestionable vitalidad de la historiografía independentista, sino también la insustituible labor que en ella ha significado la septuagenaria Historia Mexicana.

\section{REFERENCIAS}

Annino, Antonio y Rafael Rojas, La Independencia. Los libros de la patria, México, Fondo de Cultura Económica, Centro de Investigación y Docencia Económicas, 2008.

Ávila, Alfredo, "Interpretaciones recientes en la historia del pensamiento de la emancipación”, en Ávila y Guedea (coords.), 2007, pp. 17-39.

Ávila, Alfredo, “Las revoluciones hispanoamericanas vistas desde el siglo xxI”, en Revista Digital de Historia Iberoamericana, 1: 1 (2008), pp. 10-39. 
Ávila, Alfredo, “¿Autonomía o independencia? Construcciones historiográficas”, en Cagiao Vila y Portillo Valdés (coords.), 2012, pp. 99-118.

Ávila, Alfredo y Virginia Guedea (coords.), La independencia de México. Temas e interpretaciones recientes, México, Universidad Nacional Autónoma de México, 2007.

Ávila, Alfredo y Virginia GuedeA, "De la independencia nacional a los procesos autonomistas novohispanos: balance de la historiografía reciente", en Chust y Serrano (eds.), 2007, pp. 255-276.

Cagiao Vila, Pilar y José María Portillo Valdés (coords.), Entre imperio y naciones. Iberoamérica y el Caribe en torno a 1810, Santiago de Compostela, Universidad de Santiago de Compostela, 2012.

Chust, Manuel y José Antonio Serrano (eds.), Debates sobre las independencias iberoamericanas, Madrid, Frankfurt, Iberoamericana Vervuert, 2007.

Guedea, Virginia, "La historia política sobre el proceso de la independencia", en Ávila y Guedea (coords.), 2007, pp. 41-64.

Hernández Jaimes, Jesús, “Los grupos populares y la insurgencia. Una aproximación a la historiografía social”, en Ávila y GUEDEA (coords.), 2007, pp. 65-84.

Moreno Gutiérrez, Rodrigo, "La historiografía del siglo xxi sobre la independencia de México", en HistoriAgenda, 38, cuarta época (oct. 2018-mar. 2019), pp. 24-35.

Rojas, Rafael, "Historiografía de la Independencia (siglo xx)", en AnNino y RoJas, 2008, pp. 97-137.

Serrano Ortega, José Antonio, "Deshaciendo el consenso. La historiografía sobre el proceso de independencia de la Nueva España, 1953-1997", en Mexican Studies/Estudios Mexicanos, 29: 1 (invierno 2013), pp. 120-148. 